\title{
Myocardial calcium signaling in physiology and disease
}

This article was published in the following Dove Press journal:

Journal of Receptor, Ligand and Channel Research

12 September 2013

Number of times this article has been viewed

\author{
Soojeong Kang' \\ Djamel Lebeche $e^{1,2}$ \\ 'Cardiovascular Research Institute, \\ ${ }^{2}$ Graduate School of Biological \\ Sciences, Icahn School of Medicine \\ at Mount Sinai, New York, NY, USA
}

Correspondence: Djamel Lebeche

Cardiovascular Research Institute, Icahn School of Medicine at Mount Sinai, I470 Madison Ave, Hess-CSM7-I I4, New York, NY 10029, USA

$\mathrm{Tel}+\mathrm{I} 2128248905$

Fax + I 212 24| 4080

Email djamel.lebeche@mssm.edu

\begin{abstract}
It is now well-established that calcium $\left(\mathrm{Ca}^{2+}\right)$ is a critical regulator of myocardial function and that abnormalities in cardiomyocyte intracellular $\mathrm{Ca}^{2+}$ dynamics contribute to pathophysiologic changes observed in several cardiac diseases, including cardiac hypertrophy, chronic heart failure, and ventricular tachyarrhythmias. Although $\mathrm{Ca}^{2+}$ plays a key role in maintaining cardiac excitation-contraction coupling, it is increasingly apparent that changes in myocardial $\mathrm{Ca}^{2+}$ also contribute to the regulation of normal and pathological signal transduction that controls myocyte growth, hypertrophic signaling, mitochondrial energetics, and transcriptional gene expression. Interestingly, experimental evidence suggests that these multifarious $\mathrm{Ca}^{2+}$-dependent responses are spatially and temporally mediated by distinct cellular $\mathrm{Ca}^{2+}$ pools (ie, microdomains), which are generated by diverse channels and molecular signals with widely differing timescales of activation. These concepts are discussed in this review, as well as the emerging role of microRNAs in cardiac remodeling and myocardial $\mathrm{Ca}^{2+}$ dynamics.
\end{abstract}

Keywords: calcium signaling, calcium microdomains, hypertrophy, heart failure, arrhythmia, microRNAs

\section{Introduction}

Calcium $\left(\mathrm{Ca}^{2+}\right)$ and $\mathrm{Ca}^{2+}$-dependent signaling are vital for the proper functioning of a healthy heart. Abnormalities in the regulation of $\mathrm{Ca}^{2+}$ homeostasis are associated with myocardial pathologies such as hypertrophy, heart failure, and ventricular arrhythmias. ${ }^{1-3}$ Intracellular $\mathrm{Ca}^{2+}$ concentrations are therefore tightly regulated by a number of $\mathrm{Ca}^{2+}$-handling enzymes, channels, and transporters located in the plasma membrane and in $\mathrm{Ca}^{2+}$ storage organelles, which work in concert to fine-tune a temporally and spatially precise $\mathrm{Ca}^{2+}$ signal during each cardiomyocyte and relaxation cycle. In addition to the well-defined $\mathrm{Ca}^{2+}$ transporters, new regulators have recently been identified and demonstrated to be essential for the homeostatic control of $\mathrm{Ca}^{2+}$ levels. Physiological maintenance of a proper cardiomyocyte $\mathrm{Ca}^{2+}$ signaling system not only is vital for cardiac cell contraction but also is crucial for controlling longterm myocyte responses such as metabolism, transcription, and growth. Emerging studies reveal that these $\mathrm{Ca}^{2+}$-dependent responses are temporally mediated by distinct $\mathrm{Ca}^{2+}$ pools (ie, microdomains), which are generated by diverse channels with widely differing timescales of activation. ${ }^{4-6}$ In this review, we discuss how myocardial $\mathrm{Ca}^{2+}$ signaling is essential for proper and coordinated cardiomyocyte function, as aberrant $\mathrm{Ca}^{2+}$-dependent responses are linked to debilitating human diseases such as pathological cardiac hypertrophy and heart failure. We also highlight the emerging role of a number 
of microRNAs and proteins, both old and new, in the dynamic control of the myocardial $\mathrm{Ca}^{2+}$ signaling system.

\section{Myocardial $\mathrm{Ca}^{2+}$ cycling in physiology \\ $\mathrm{Ca}^{2+}$-induced $\mathrm{Ca}^{2+}$ release}

Excitation-contraction (EC) coupling is a well-described, fundamental principle by which a myocyte's ionic (excitation) properties tightly coordinate its mechanical (contraction) function. In the mammalian heart, a number of ion channels and transporters ensure that calcium release and uptake in myocytes is carefully regulated during the process of contraction, as excessive quantities of calcium can lead to deleterious pathological consequences. ${ }^{7}$ The sarcoplasmic reticulum (SR) plays an important role in orchestrating the movement of calcium during each contraction and relaxation.

Excitation leads to the opening of voltage-gated L-type $\mathrm{Ca}^{2+}$ channels, allowing the entry of a small amount of $\mathrm{Ca}^{2+}$ into the cell. ${ }^{7}$ Through a coupling mechanism between the L-type $\mathrm{Ca}^{2+}$ channel (LTCC) and the $\mathrm{SR} \mathrm{Ca}^{2+}$ release channel (ryanodine receptor 2 [RyR2]), a larger amount of $\mathrm{Ca}^{2+}$ is released through a process termed $\mathrm{Ca}^{2+}$-induced $\mathrm{Ca}^{2+}$ release (CICR), activating the myofilaments and leading to contraction. ${ }^{7}$ This process increases intracellular $\mathrm{Ca}^{2+}$ concentration from approximately $10 \mathrm{nM}$ during diastole to about $1 \mu \mathrm{M}$ during systole. The relatively increased $\mathrm{Ca}^{2+}$ concentration in the t-tubular SR junctions inactivates the LTCC by a $\mathrm{Ca}^{2+}$-dependent inactivation and terminates there by $\mathrm{Ca}^{2+}$ influx to avoid $\mathrm{Ca}^{2+}$ overload and arrhythmias. ${ }^{7,8}$ During relaxation, $\mathrm{Ca}^{2+}$ is reaccumulated back into the $\mathrm{SR}$ by the $\mathrm{SR} \mathrm{Ca}^{2+}$ adenosine triphosphatase (ATPase) pump (SERCA2a) and extruded extracellularly primarily by the sarcolemmal $\mathrm{Na}^{+} / \mathrm{Ca}^{2+}$ exchanger-1 (NCX1). The plasma membrane $\mathrm{Ca}^{2+}$-ATPase pump and the mitochondrial uniporter may also contribute to this process, albeit minimally. ${ }^{7}$ The contribution of each of these mechanisms for lowering cytosolic $\mathrm{Ca}^{2+}$ varies by species and is mostly determined by the abundance and activity of SERCA2a and sarcolemmal $\mathrm{NCX} 1$, by intracellular concentrations of $\mathrm{Na}^{+}$and $\mathrm{Ca}^{2+}$, and by the membrane potential. ${ }^{7,9}$ In humans, $\sim 75 \%$ of the $\mathrm{Ca}^{2+}$ is removed by SERCA2a and $\sim 25 \%$ by the $\mathrm{NCX} 1 .{ }^{10,11} \mathrm{The}^{\mathrm{Ca}^{2+}}$ pumping activity of SERCA2a is influenced by phospholamban (PLN) ${ }^{12}$ and sarcolipin. ${ }^{13}$ In the unphosphorylated state, PLN inhibits SERCA2a activity, whereas phosphorylation of phospholamban by cyclic adenosine monophosphate (cAMP)dependent protein kinase and by $\mathrm{Ca}^{2+}$-calmodulin-dependent protein kinase (CaMKII) reverses this inhibition. ${ }^{12}$ CaMKII can also directly phosphorylate SERCA2a and enhances its activity. ${ }^{14,15}$ Sarcolipin, in contrast, inhibits SERCA2a through direct binding and through stabilization of SERCA2a-PLN interaction in the absence of PLN phosphorylation and through the inhibition of PLN phosphorylation. ${ }^{13}$ Disease-induced malfunction of several of these key EC coupling proteins and the subsequent alterations in intracellular $\mathrm{Ca}^{2+}$ homeostasis results in mechanical and electrical dysfunction at the molecular and the cellular levels and in the entire organ.

Although $\mathrm{Ca}^{2+}$ regulation of EC coupling is fundamental for cardiac physiology, $\mathrm{Ca}^{2+}$ is also essential for the regulation of an array of $\mathrm{Ca}^{2+}$-dependent regulatory processes associated with cardiac remodeling. There is emerging evidence that the induction of this $\mathrm{Ca}^{2+}$-dependent remodeling is not affected by the rapid elevation in the contractile $\mathrm{Ca}^{2+}$ stimulus but is mediated by a more sustained $\mathrm{Ca}^{2+}$ signal. Several reports have now described the existence of spatially restricted and distinct $\mathrm{Ca}^{2+}$ pools in cardiomyocytes distinctly contractility and $\mathrm{Ca}^{2+}$-dependent signaling pathways. How the cardiac myocyte distinguishes between contractile $\mathrm{Ca}^{2+}$ and signaling $\mathrm{Ca}^{2+}$ has been a matter of debate, and few hypotheses have been put forward to explain this conundrum. ${ }^{4,6,16}$ However, a picture is now emerging that emphasizes how spatially restricted $\mathrm{Ca}^{2+}$ signals in local $\mathrm{Ca}^{2+}$ nanodomains, microdomains, and macrodomains can selectively recruit certain transcription factors and not others, or can activate certain metabolic molecules and not others, through activation of diverse $\mathrm{Ca}^{2+}$-permeable ion channels with widely differing timescales of activation. A classic example of the concept of $\mathrm{Ca}^{2+}$ microdomains is represented by the maintenance of a very close approximation of LTCC and RyR2 in the dyads between t-tubular sarcolemma and the junctional SR that promotes contraction. ${ }^{17,18}$ A similar microdomain also exists between mitochondria and the SR that facilitates an efficient and rapid mitochondrial $\mathrm{Ca}^{2+}$ uptake to meet the bioenergetics demand of the beating myocyte. ${ }^{19,20}$ Other examples of $\mathrm{Ca}^{2+}$ microdomains involve local $\mathrm{Ca}^{2+}$ pools provided and regulated by (1) LTCC, ${ }^{21,22}$ T-type calcium channel, ${ }^{23}$ and plasma membrane $\mathrm{Ca}^{2+}$-ATPase isoform $4^{5,24-26}$ in nonjunctional sarcolemmal caveolae; (2) transient receptor potential channel proteins (TRPCs); ${ }^{.27,28}$ and (3) inositol 1,4,5-triphosphate receptor ( $\mathrm{IP}_{3} \mathrm{R}$ ) localized to the nuclear membrane, ${ }^{29,30}$ which are all believed to be implicated in mediating diverse $\mathrm{Ca}^{2+}$ responsive signal transduction in hypertrophy and heart failure.

\section{$\mathrm{Ca}^{2+}$-induced $\mathrm{Ca}^{2+}$ entry}

Although calcium signaling is a combination of a highly organized $\mathrm{Ca}^{2+}$ release from intracellular $\mathrm{Ca}^{2+}$ stores, SR, 
and $\mathrm{Ca}^{2+}$ entry across the plasma membrane, extracellular $\mathrm{Ca}^{2+}$ influx is necessary to maintain cytosolic $\mathrm{Ca}^{2+}$ levels. In nonexcitable cells, the mechanism that controls $\mathrm{Ca}^{2+}$ entry is triggered by intracellular $\mathrm{Ca}^{2+}$ store depletion, which activates plasma membrane $\mathrm{Ca}^{2+}$ channels and elicits a prolonged increase in intracellular $\mathrm{Ca}^{2+}$ in a process now termed store-operated $\mathrm{Ca}^{2+}$ entry (SOCE). This mechanism of $\mathrm{Ca}^{2+}$ influx plays a critical role in replenishing $\mathrm{Ca}^{2+}$ stores and providing sustained and precise local $\mathrm{Ca}^{2+}$ signals that are critical in determining a spectrum of downstream cellular responses. Stromal interacting molecule (STIM1), a recently identified single-span endoplasmic reticulum (ER) membrane molecule, has a unique and essential role in mediating $\mathrm{Ca}^{2+}$ entry through SOCE. ${ }^{31,32}$

STIM1 contains four low- $\mathrm{Ca}^{2+}$-affinity luminal EF hands that are sensitive to ER $\mathrm{Ca}^{2+}$ concentration. ${ }^{33}$ When $\mathrm{ER} \mathrm{Ca}^{2+}$ is high, $\mathrm{Ca}^{2+}$ binds to STIM1 EF hands and inactivates it. However, when ER $\mathrm{Ca}^{2+}$ is decreased, $\mathrm{Ca}^{2+}$ dissociates from the EF hands and causes conformational changes that result in the activation of STIM1. Thus, STIM1 functions as a sensor of $\mathrm{Ca}^{2+}$ levels in the lumen of the ER and activator of the SOCE channel in the plasma membrane. ${ }^{34,35}$ STIM1, through its $\mathrm{Ca}^{2+}$-binding EF hands, can detect small changes in $\mathrm{ER} \mathrm{Ca}^{2+}$ levels and responds by rapidly oligomerizing and translocating into specialized regions close to the ERplasma membrane junctions, where it interacts with and activates plasma membrane Orai channels. ${ }^{36-38}$ Interaction of STIM1 with Orai $\mathrm{Ca}^{2+}$ channels then triggers entry of $\mathrm{Ca}^{2+}$ and replenishment of intracellular $\mathrm{Ca}^{2+}$ homeostasis and activation of $\mathrm{Ca}^{2+}$-dependent signaling pathways. ${ }^{39,40} \mathrm{As} \mathrm{Ca}^{2+}$ levels increase in the ER lumen or at ER-plasma membrane junctions (microdomains), STIM1-Orai coupling is turned off and STIM1-induced Orai channel activation is terminated, leading to STIM1 protein de-oligomerization. ${ }^{41-44}$

Whether cardiomyocytes possess a similar functional SOCE mechanism is not clear, as $\mathrm{Ca}^{2+}$ entry through SOCE requires depletion of SR/ER $\mathrm{Ca}^{2+}$ store content, a condition that is hardly achieved in vivo in physiological conditions. However, SOCE has emerged as a potential mechanism regulating $\mathrm{Ca}^{2+}$ transients in cardiomyocytes, and a number of recent studies have provided evidence that SOCE is, for instance, operational in neonatal cardiomyocytes. ${ }^{45-48}$ Hulot et al have reported that STIM1 is abundant in neonatal cardiomyocytes but marginally expressed in adult cardiomyocytes. ${ }^{48}$ Interestingly, these studies also reported that STIM1 manipulation did not have any influence on cardiac EC coupling. These observations were further confirmed by Luo et al, who have also demonstrated that SOCE is nearly absent in adult cardiomyocytes but is highly active in neonatal myocytes or adult cardiomyocytes under pathological cardiac remodeling. ${ }^{49}$ This latter study also demonstrated that STIM1 expression levels correlate with the magnitude of SOCE activation and the subsequent increase in $\mathrm{Ca}^{2+}$ entry. ${ }^{49}$

Although the SOCE process has been initially reported to mainly result from the coupling of STIM1 with Orai $\mathrm{Ca}^{2+}$ channels, ${ }^{47,50,51}$ STIM1 is now known to interact with and activate several TRPCs (transient receptor potential channels), which have long been linked to SOCE. ${ }^{52,53}$ Recent evidence suggests, for example, that TRPC1, TRPC3, and TRPC6 are implicated in cardiac hypertrophic responses. ${ }^{54-58}$ However, even though STIM1appears to function as a master regulator of SOCE protein complexes, many questions pertaining to its role in cardiomyocytes invite future answers. For instance, what are the coupling partners of STIM1 in the heart? Do Orai and TRP channels act synergistically, or redundantly, and do they have different timescales of activation? Do they activate a common $\mathrm{Ca}^{2+}$ pool, and/or do they elicit different $\mathrm{Ca}^{2+}$-dependent signaling pathways? What is the role of STIM2, Orai1, Orai2 and Orai3, and other TRP channels in the heart?

Emerging results from a number of studies show that adult cardiomyocytes may not need SOCE per se to regulate SR $\mathrm{Ca}^{2+}$ loading or contractile $\mathrm{Ca}^{2+}$ pools, but this process has a functional significance in fetal and neonatal cardiomyocytes and during cardiac growth and remodeling. ${ }^{7}$ Moreover, studies have reported that STIM1 interacts with and controls the function of Cav1.2 voltage-operated $\mathrm{Ca}^{2+}$ channel (LTCC) in smooth muscle and neuron. ${ }^{59,60}$ STIM1 interacts with the C-terminal end of the LTCC, inhibiting its function and decreasing its surface expression, thus leading to its inactivation. ${ }^{60}$ Interestingly, this action of STIM1 on LTCC is thought to favor $\mathrm{Ca}^{2+}$ entry via the Orai channel. ${ }^{60}$ Given the importance of LTCC in $\mathrm{Ca}^{2+}$ signaling in cardiac hypertrophy, it is not known whether STIM1 has a similar effect on LTCC in cardiomyocytes, an observation that remains to be determined.

\section{$\mathrm{Ca}^{2+}$ signaling in hypertrophy and heart failure Intracellular $\mathrm{Ca}^{2+}$ handling in hypertrophy and heart failure}

The remarkable low cytosolic $\mathrm{Ca}^{2+}$ gradient is tightly maintained, as noted earlier, by the concerted activity of several highly conserved families of $\mathrm{Ca}^{2+}$ handling pumps, channels, and transporters that regulate a balance between $\mathrm{Ca}^{2+}$ entry, extrusion, and storage. ${ }^{61}$ Although initial modifications of 
$\mathrm{Ca}^{2+}$ handling are beneficial, several lines of evidence now suggest that $\mathrm{Ca}^{2+}$ dysregulation contributes to pathological hypertrophy and heart failure.

Heart failure is characterized by a number of abnormalities at the cellular level in the various steps of EC coupling. The major abnormality in $\mathrm{Ca}^{2+}$ cycling that occurs in heart failure is the observation that $\mathrm{SR} \mathrm{Ca}{ }^{2+}$ stores are significantly reduced. When these stores are depleted, $\mathrm{SR} \mathrm{Ca}^{2+}$ release is curtailed in terms of both its amplitude and duration, and as a result, reduced contraction force is generated. The likely cause of this deficiency (depressed SR load) is the differential changes in gene expression and activity of key $\mathrm{Ca}^{2+}$ regulatory proteins. $\mathrm{Ca}^{2+}$ transients recorded from failing human myocardial cells or trabeculae reveal a significantly prolonged $\mathrm{Ca}^{2+}$ transient with an elevated end-diastolic intracellular $\mathrm{Ca}^{2+}$. A decrease in SERCA2a activity and $\mathrm{Ca}^{2+}$ uptake have been shown to be responsible for abnormal $\mathrm{Ca}^{2+}$ homeostasis in both experimental and human failing hearts. ${ }^{62,63}$ Associated with a defective $\mathrm{Ca}^{2+}$ uptake, there is a decrease in the relative ratio of SERCA2a/PLN in these failing hearts. With a decrease in SERCA2a expression and an increase in PLN expression, the SERCA2a/PLN ratio is significantly decreased, leading to a slower relaxation.

Using transgenic, and gene transfer approaches in isolated rat cardiac myocytes and failing human myocytes, increasing levels of PLN relative to SERCA2a significantly altered intracellular $\mathrm{Ca}^{2+}$ handling by prolonging the relaxation phase of the $\mathrm{Ca}^{2+}$ transient, decreasing $\mathrm{Ca}^{2+}$ release, and increasing resting calcium. ${ }^{10-12,61}$ Overexpression of SERCA2a for instance in neonatal rat cardiomyocytes largely "rescued" the phenotype created by decreasing the SERCA2a/PLN ratio. ${ }^{64}$ More important, in human cardiomyocytes isolated from the left ventricle of patients with end-stage heart failure, gene transfer of SERCA2a resulted in an increase in both protein expression and pump activity and induced a faster contraction velocity and enhanced relaxation velocity, thereby restoring these parameters to levels observed in nonfailing hearts. ${ }^{65}$ In an animal model of pressure-overload hypertrophy in transition to failure, in which SERCA2a protein levels and activity are decreased and severe contractile dysfunction is present, overexpression of SERCA2a by gene transfer in vivo restored both systolic and diastolic function to normal levels. ${ }^{62,63}$ These studies provide strong evidence that overexpression of SERCA2a to rescue disturbed $\mathrm{Ca}^{2+}$ cycling and myocardial function of the failing heart is indeed possible, validating the feasibility of cardiac gene transfer in patients with heart failure. ${ }^{66,67}$ The recent successful and safe completion of a Phase II trial targeting the cardiac SERCA2a has the potential to open a new era for gene therapy for heart failure. ${ }^{67-69}$ In contrast to SERCA2a, most studies from hypertrophied and failing hearts have shown an increase in both NCX1 messenger (m)RNA and protein, ${ }^{70,71}$ suggesting that enhanced NCX1 function compensates for defective SR removal of $\mathrm{Ca}^{2+}$ from the cytoplasm in the failing heart, but at the cost of further depleting the SR-releasable pool of $\mathrm{Ca}^{2+}$ and further increasing the probability of arrhythmogenicity. However, the exact role of NCX1 in disease and whether it participates as a compensatory or maladaptive mechanism remains controversial.

It was demonstrated that RyR2 phosphorylation is highly increased in heart failure and that this "hyperphosphorylation" increases the RyR2 gating activity and causes a persistent leak of $\mathrm{Ca}^{2+}$ from the SR, further impairing the $\mathrm{SR} \mathrm{Ca}^{2+}$ load. ${ }^{72}$ Usually, the RyR is closed during diastole to allow for SERCA2a $\mathrm{Ca}^{2+}$ uptake. $\mathrm{Ca}^{2+}$ release through $\mathrm{RyR} 2$ is regulated in part by the interaction of RyR2 with calstabin2 (also known as FKBP12.6). Protein kinase A (PKA)-induced hyperphosphorylation of RyR2 in failing hearts causes calstabin2 to dissociate from the RyR2 channel complex and destabilize the closed state of the channel, resulting in increased spontaneous diastolic RyR2 activity, elevated diastolic SR Ca ${ }^{2+}$ leak, reduced SR Ca ${ }^{2+}$ load, and decreased $\mathrm{Ca}^{2+}$ transients. ${ }^{1,73,74}$ Other suggested mechanisms for increased RyR2 open probability include oxidative modification of the RyR and increased RyR phosphorylation by CaMKII. ${ }^{75}$ Furthermore, the gating of RyR2 is also controlled by a score of other $\mathrm{Ca}^{2+}$ regulatory proteins including triadin/junction/ calsequestrin complex, sorcin, calmodulin, and the protein phosphatases PP1 and PP2A. ${ }^{76,77}$ Diastolic leak of SR Ca ${ }^{2+}$ has been proposed as the mechanism responsible for delayed after-polarization, ventricular arrhythmia trigger, and sudden death in heart failure. ${ }^{78}$ Although substantial data have accumulated in support of the RyR hyperphosphorylation hypothesis, many reports have questioned it and, using a similar canine model of heart failure (in addition to human tissue), have found that the $\mathrm{Ca}^{2+}$ sensitivity of the RyR opening was unaffected. ${ }^{78,79}$ Furthermore, the association of calstabin2 with RyR2 has been reported to be insensitive to the degree of PKA phosphorylation. ${ }^{80}$ Although impaired RyR function is likely to be involved in the abnormal $\mathrm{Ca}^{2+}$ handling commonly observed in heart failure, the exact alterations in RyR function in heart failure have yet to be defined.

Another mechanism for aberrant $\mathrm{Ca}^{2+}$ signaling in heart failure is the function of inositol 1,4,5-triphosphate gated $\mathrm{Ca}^{2+}$ release channels $\left(\mathrm{IP}_{3} \mathrm{R}\right)$ located in the $\mathrm{SR}$ and nuclear envelope. Although the physiological role of $\mathrm{IP}_{3} \mathrm{R}$ 
in cardiomyocytes has been a matter of debate, recent evidence supports a prominent role ${ }^{81}$ in EC coupling and $\mathrm{SR} \mathrm{Ca}^{2+}$ release: their location near the RyR2 within the dyadic functional microdomains suggests that they can trigger CICR and enhance EC coupling. ${ }^{82-84}$ The expression of $\mathrm{IP}_{3} \mathrm{R}$, which is typically many-fold less abundant than RyR in normal cardiomyocytes, ${ }^{29,84}$ increases significantly in both human and animal models of hypertrophy and heart failure, particularly their expression in the dyadic junction, suggesting that these channels may be associated with pathological signaling. ${ }^{85,86}$ Studies in neonatal rat ventricular myocytes suggest that activation of $\mathrm{IP}_{3} \mathrm{R}$ may be linked to $\alpha 1$ adrenergic receptor $(\alpha 1 \mathrm{AR})$-induced $\mathrm{Ca}^{2+}$ spark rate and global $\mathrm{Ca}^{2+}$ oscillations, as well as catecholamine-induced cardiomyocyte hypertrophic growth. ${ }^{87}$ Heart-specific genetic manipulations of $\mathrm{IP}_{3} \mathrm{R}$ signaling demonstrate that $\mathrm{IP}_{3} \mathrm{R}$ expression enhances cardiac hypertrophy remodeling in vivo in response to agonist stimulation. ${ }^{30}$ Increased $\mathrm{IP}_{3}$-induced $\mathrm{Ca}^{2+}$ release in the perinuclear region can directly activate $\mathrm{Ca}^{2+}$-dependent transcription factors that permit expression of hypertrophic genes. ${ }^{83,85}$ However, enhanced SR Ca ${ }^{2+}$ release through $\mathrm{IP}_{3} \mathrm{R}$ has the potential to trigger arrhythmogenic events. ${ }^{85}$

\section{New players in cardiomyocyte $\mathrm{Ca}^{2+}$ dynamics and cardiomyopathy}

New findings have illustrated the regulatory roles of novel candidates in myocyte $\mathrm{Ca}^{2+}$ cycling and cardiac pathophysiology. Only a few examples of relevance to the topic of this review are addressed here.

\section{TRPC}

Very recently, another family of intracellular $\mathrm{Ca}^{2+}$ permeable ion channels, unrelated to RyR and $\mathrm{IP}_{3} \mathrm{R}$, has been implicated in myocardial $\mathrm{Ca}^{2+}$ signaling and cardiac physiology and pathology: the TRPCs. At least five subclasses of TRPC are highly expressed in the heart. ${ }^{27,88}$ TRPCs have been mapped to different structures in the cell, such as the plasma membrane, or assembled with caveolar complexes, ${ }^{89,90}$ the Golgi apparatus, ${ }^{91}$ and the SR/ER. ${ }^{92}$ Although the TRPC channels do not appear necessary for the regulation of $\mathrm{SR} \mathrm{Ca}^{2+}$ cycling and EC coupling, they clearly contribute to the dynamics of local $\mathrm{Ca}^{2+}$ pools and the stimulation of $\mathrm{Ca}^{2+}$-dependent signaling pathways associated with cardiac hypertrophy and heart failure. Interestingly, the activity or expression of TRPC channels is upregulated in animal models of pathological hypertrophy and heart failure and in human heart failure samples ${ }^{28,56,57,93}$ or in cultured neonatal cardiomyocytes after hypertrophic agonist stimulation. ${ }^{55,94}$ Experimental cardiac genetic manipulations in vivo have also suggested prohypertrophic effects of TRPC channels. For instance, TRPC 3 and TRPC6 transgenic overexpression in mice both impaired cardiac function and induced cardiomyopathy, most likely through activation of the calcineurin-nuclear factor of activated T-cells (NFAT) module. ${ }^{54,57}$ Conversely, genetic deletion of TRPC1, selective inhibition of TRPC3, or inhibition of TRPC6 effectively blocked cardiac hypertrophy and attenuated calcineurin-NFAT activation in mice subject to transverse aortic constriction (TAC) surgery. ${ }^{56,93,95,96}$ Similarly, silencing TRPC3 and TRPC6 in vitro in cultured neonatal cardiomyocytes abrogated angiotensin II-dependent hypertrophic response and calcineurin-NFAT signaling, ${ }^{58}$ whereas activation of TRPC3 or TRPC7 promoted cardiomyocyte apoptosis that could contribute to myocardial injury. ${ }^{28,97,98}$ Thus, TRPC channels are emerging as prohypertrophic effectors and key components in $\mathrm{Ca}^{2+}$ signaling pathways in maladaptive programming of cardiac growth.

\section{$\mathrm{ClBI}$}

$\mathrm{Ca}^{2+}$ and integrin-binding protein 1 (CIB1, also called calmyrin) is a sarcolemmal protein that has been identified as a regulator of calcineurin-NFAT signaling and cardiac hypertrophy in the heart. ${ }^{99} \mathrm{CIB} 1$ interacts with the calcineurin regulatory subunit (calcineurin B) and regulates its activity. Calcineurin has been previously reported to interact with LTCC and activates its $\mathrm{Ca}^{2+}$ gating properties. ${ }^{22}$ Given its location on the plasma membrane, CIB1 is believed to interact with LTCC and recruits calcineurin to the channel for activation. Genetic manipulations have demonstrated that deletion of CIB1 led to significant reduction in calcineurinNFAT activation and prevented calcineurin translocation to the membrane, whereas overexpression of CIB1 produced the opposite effect. ${ }^{99}$ This study established CIB1 as a new regulator of pathological cardiac hypertrophy and calcineurinNFAT signaling in the heart.

\section{Epac}

Epac (exchange protein directly activated by cAMP), a cAMP target, has emerged as a new regulator of cardiac dysfunction. Two Epac isoforms have been identified: Epac1 (with one cAMP-binding domain) and Epac2 (with two cAMP-binding sites). ${ }^{100}$ Recent evidence shows Epac is involved in the regulation of myocardial $\mathrm{Ca}^{2+}$ handling and cardiac hypertrophy. ${ }^{101-103}$ Pharmacological activation of Epac1 with the cAMP analog 8-(4-chlorophenylthio)-2'-Omethyladenosine- $3^{\prime}, 5^{\prime}$-cyclic mono-phosphate was shown to enhance $\mathrm{SR} \mathrm{Ca}^{2+}$ release via phospholipase $\mathrm{C}^{102,104}$ and 
CaMKII, ${ }^{103,104}$ suggesting that Epac1-induced SR Ca ${ }^{2+}$ leak can also reduce $\mathrm{SR} \mathrm{Ca}^{2+}$ load and release. ${ }^{105}$ These effects are similar to those evoked by $\beta$-adrenergic receptor $(\beta-A R)$ activation. Indeed, $\beta$-AR stimulation activated Epac1 and altered $\mathrm{SR} \mathrm{Ca}^{2+}$ leak by increasing CaMKII-dependent phosphorylation of RyR2. ${ }^{103,104,106}$

Previous studies have demonstrated that chronic activation of $\beta$-AR, as it occurs in heart failure conditions, can provoke cardiac arrhythmias as a result of abnormal diastolic $\mathrm{SR} \mathrm{Ca}^{2+}$ leaks via phosphorylation of RyR2, ${ }^{107,108}$ raising the possibility that the Epac1-induced $\mathrm{SR} \mathrm{Ca}^{2+}$ leak pathway also may contribute significantly to $\beta$-AR-induced arrhythmias. Indeed, pharmacological activation of Epac1 in whole hearts increased diastolic SR Ca ${ }^{2+}$ leak and ventricular arrhythmogenesis. ${ }^{106,109}$ Although there is a general agreement on the role of Epac in myocyte $\mathrm{Ca}^{2+}$ mishandling, its role in pathological remodeling is less certain. Epac is upregulated in experimental animal models of hypertrophy ${ }^{110}$ and in late-stage failing human heart samples. ${ }^{111}$ Furthermore, Epac1 overexpression induced hypertrophic response in cultured neonatal ${ }^{101}$ and adult cardiomyocytes, ${ }^{110}$ whereas Epac1 silencing protected against $\beta$-AR-induced hypertrophy. ${ }^{110}$ However, recent work in Epac knockout mice has shown that Epac has no effect on cardiac function, baseline myocyte $\mathrm{Ca}^{2+}$ signaling, or earlystage pressure overload-induced hypertrophy, ${ }^{109}$ but plays a more substantial role in pathological conditions such as arrhythmia and heart failure. ${ }^{106,109}$ Furthermore, this study also demonstrated that Epac2 isoform, and not Epac1, mediates $\mathrm{SR} \mathrm{Ca}^{2+}$ leak via $\beta_{1}$-AR, causing CaMKII-dependent RyR2 phosphorylation and SR $\mathrm{Ca}^{2+}$ leak and arrhythmia. ${ }^{109}$ Epac1 is, however, believed to mediate a $\mathrm{Ca}^{2+}$ pool that is involved in transcriptional signaling. ${ }^{112}$ Indeed, Epac1 can effectively activate the hypertrophic transcriptional signaling such as calcineurin-NFAT and CaMKII-histone deacetylase pathways, possibly via an $\mathrm{IP}_{3}-\mathrm{IP}_{3} \mathrm{R}$ modulation. ${ }^{105,113}$

\section{Electrical remodeling and ionic imbalance in hypertrophy and heart failure}

Although changes in many ion channel currents have been reported in cardiac hypertrophy, reduction in the density of the transient outward $\mathrm{K}^{+}$current $\left(I_{t o}\right)$ is the most prominent ionic current change resulting in action potential duration (APD) prolongation in a process referred to as electrical remodeling. ${ }^{114-116}$ Prolongation of the APD is consistently observed in experimental models of cardiac hypertrophy and failure. APD prolongation and downregulation of $I_{t o l}$ are also observed in compensated hypertrophy ${ }^{117}$ and in end-stage human heart failure. ${ }^{118}$ In the mammalian heart, $I_{t o 1}$ is encoded by Kv4.2,
Kv4.3, or a combination of the two. ${ }^{119}$ Associated with the reduction in $I_{\text {tol }}$ density, downregulation of Kv4.2 and/or Kv4.3 mRNA and protein expression levels has been observed in cardiac tissue derived from diseased hearts. ${ }^{115,120,121}$ APD has been shown to strongly influence $\mathrm{Ca}^{2+}$ transient amplitude in normal ${ }^{122}$ and hypertrophied ${ }^{120}$ myocytes, which may help support contraction of the compromised myocardium but may also harm the myocardium by increasing the propensity to develop arrhythmias ${ }^{119}$ and by activating hypertrophic signaling pathways.

The relationships between reductions of $I_{t o 1}$ and concomitant APD prolongation and cardiac hypertrophy and heart failure have been explored using a number of techniques. Cardiac-specific ablation of $I_{t o 1}$ by overexpression of a Kv4.2 channel with a single missense mutation (W362F) did not induce cardiac hypertrophy. ${ }^{123}$ However, cardiac specific overexpression of dominant-negative Kv4.2 channel (truncated channel: Kv4.2 N) resulted in hypertrophy and cardiomyopathy along with a prolonged APD. ${ }^{124}$ APD prolongation is associated with an enhanced propensity to develop cardiac arrhythmias, ${ }^{125,126}$ which may contribute to the high incidence of sudden death observed in patients with heart failure. ${ }^{119,127}$ The mechanism by which APD prolongation contributes to arrhythmogenesis might be related to the intracellular $\mathrm{Ca}^{2+}$ overload it generates. APD prolongation can elevate $\left[\mathrm{Ca}^{2+}\right]_{\mathrm{i}}$, and several groups have demonstrated that modulation of APD is an important determinant of calcium influx through LTCC. ${ }^{128,129}$ We have shown that cardiac gene transfer of Kv4.3-based $I_{\text {to }}$ can increase $I_{\text {to }}$ density, shorten APD, decrease $\mathrm{Ca}^{2+}$ influx, and attenuate cardiac hypertrophy in vitro ${ }^{130}$ and in vivo. ${ }^{131}$ Interestingly, restoration of the otherwise downregulated expression of the potassium channel interacting protein 2 (KChIP2, a $\mathrm{K}_{\mathrm{V}} 4$ subunit) in hypertrophied hearts, evoked similar effects. ${ }^{132}$ Therefore, a reduction in $I_{\text {to }}$ density and APD prolongation represent early electrical remodeling events in the diseased myocardium, pointing toward a potential role in disease initiation and progression.

\section{$\mathrm{Ca}^{2+}$ signaling in cardiac arrhythmia Pathogenesis and the role of calcium overload during cardiac arrhythmia}

Ventricular arrhythmias are a major cause of death in patients with heart failure. The role of abnormal cytoplasmic $\mathrm{Ca}^{2+}$ regulation is thought to be a critical and perhaps common mechanism underlying cardiac dysfunction and the genesis of ventricular arrhythmias. ${ }^{133}$ In fact, the well-described phenomenon of $\mathrm{Ca}^{2+}$-mediated arrhythmias was originally 
observed as a result of digitalis intoxication. By raising intracellular $\mathrm{Na}^{+}$, cardiac glycosides reduce $\mathrm{Ca}^{2+}$ efflux by NCX and favor net $\mathrm{Ca}^{2+}$ uptake by the SR. At high doses, these agents can produce $\mathrm{Ca}^{2+}$ overload of the $\mathrm{SR}$ and result in the spontaneous release of $\mathrm{Ca}^{2+}$ by RyR, thereby generating a net depolarizing transient inward current mediated by NCX. Spontaneous rises in membrane potential caused by the activation of the transient inward current manifest as delayed after-depolarizations (DADs) that can be of sufficient magnitude to produce a full-blown premature action potential. A variety of complementary changes occurring as a result of left ventricular dysfunction in heart failure can reduce the threshold for the induction of DAD-mediated triggered beats, among which is the upregulation of NCX and the increased open probability of PKA-hyper-phosphorylated RyR2 channels. Catecholaminergic polymorphic ventricular tachycardia and arrhythmogenic right ventricular dysplasia, both of which are characterized by mutations in RyR2 genes, are two forms of familial cardiomyopathiesassociated arrhythmias. ${ }^{134}$ Wehrens et al demonstrated that catecholaminergic polymorphic ventricular tachycardia mutant RyR2 channels have a decreased binding affinity for calstabin2. ${ }^{135}$ Although these mutant channels are indistinguishable from wild-type channels at rest, they exhibit exaggerated calstabin 2 dissociation from RyR2 in response to PKA-mediated phosphorylation, causing more SR $\mathrm{Ca}^{2+}$ release and diastolic $\mathrm{Ca}^{2+}$ leak. ${ }^{136}$ In addition to DADs, early after-depolarizations are another source of triggered activity in cardiomyocytes, which is secondary to abnormal $\mathrm{Ca}^{2+}$ cycling and results from the reactivation of LTCC during conditions of prolonged action potential repolarization. ${ }^{137,138}$ Furthermore, abnormal $\mathrm{Ca}^{2+}$ cycling by the $\mathrm{SR}$ has also been implicated in the pathogenesis of reentrant arrhythmias by promoting action potential alternans and/or spiral wave break-ups leading to the degeneration of ventricular tachycardia and ventricular fibrillation. ${ }^{137,139,140}$ As such, changes in $\mathrm{Ca}^{2+}$ handling in general, and $\mathrm{Ca}^{2+}$ overload in particular, are thought to form the triggers for lethal arrhythmias at the cellular level, which, under appropriate conditions, might produce sustained arrhythmias at the organ-system level.

\section{Targeting myocardial calcium cycling to prevent arrhythmia}

To highlight the importance of SR $\mathrm{Ca}^{2+}$ in the regulation of ventricular arrhythmia, we have addressed the issue of restoring the $\mathrm{Ca}^{2+}$ load of the SR through SERCA2a overexpression, using genetic strategies. ${ }^{141}$ We and others have previously demonstrated that targeted delivery of SERCA2a to the heart can significantly improve contractile function in vitro and in vivo, normalize metabolism and intracellular signaling pathways, and improve survival and mechano-energetic properties at no cost of oxygen consumption. ${ }^{62,63,142,143}$ Whether these potential benefits of SERCA2a can be further extended to improve cardiac arrhythmias was addressed using a well-documented $\mathrm{Ca}^{2+}$ overload rat model of ischemia/reperfusion (IR). Cardiac IR induces ventricular arrhythmias, including ventricular premature beats, ventricular tachycardia, and ventricular fibrillation, in both experimental animal models and in $\operatorname{man}^{7}$ We found that SERCA2a overexpression significantly decreased ventricular arrhythmias during IR and 24 hours later, using continuous telemetry. ${ }^{141}$ In addition, SERCA2a overexpression significantly reduced infarct size and improved wall thickening in the anterior wall, which may have contributed to the decrease in ventricular arrhythmias because the size of the infarct is associated with the incidence and frequency of arrhythmias. A decrease in diastolic $\mathrm{Ca}^{2+}$ and better handling of intracellular ions during the rush of reperfusion are both associated with improved survival of the cardiomyocyte. The reduced incidence and severity of threatening arrhythmias of IR in the SERCA2a-overexpressing animals also corresponded to a preservation of muscle function, as demonstrated by improved wall thickening and hemodynamic measurements. These findings were recently extended by other studies that demonstrated that SERCA2a gene transfer in animal models of heart failure significantly reduced arrhythmogenic cardiac alternans, ${ }^{144}$ reduced SR $\mathrm{Ca}^{2+}$ leak through reduction of RyR phosphorylation, and attenuated ventricular arrhythmias in vivo. ${ }^{66}$

Although targeting $\mathrm{SR} \mathrm{Ca}^{2+}$ cycling proteins can abrogate $\mathrm{Ca}^{2+}$-mediated arrhythmic triggers and prevent the adverse electrophysiological remodeling associated with IR injury, other candidates have also been shown to exert beneficial antiarrhythmic effects. Protein kinase $\mathrm{C}$ epsilon (PKCE) activation confers cardioprotection from IR injury in various cell cultures, isolated perfused heart models, and transgenic mice. ${ }^{145}$ Furthermore, in vivo activation of PKCE was shown to protect the ischemic myocardium from reperfusion arrhythmias, whereas its inhibition exacerbates their incidence. ${ }^{146} \mathrm{CaMKII}$ has been functionally implicated in the mediation of frequency-dependent acceleration of relaxation, RyR2-mediated SR Ca ${ }^{2+}$ leak, and $\mathrm{Ca}^{2+}$ current facilitation, ${ }^{147}$ all of which lead to perturbations in intracellular and $\mathrm{SR} \mathrm{Ca}^{2+}$ balances and triggered arrhythmias. In addition, CaMKII expression and activity are known to increase in patients and in many animal models of structural heart disease. Hence, its inhibition has been shown in several studies to 
reduce hypertrophy, cardiac dysfunction, and importantly, ventricular arrhythmias. ${ }^{148,149}$

\section{MicroRNA-mediated $\mathrm{Ca}^{2+}$ signals and cardiac hypertrophy}

Recent studies have uncovered key roles for a family of newly discovered, small, noncoding regulatory RNA molecules, known as microRNAs (miRNAs), in the control of diverse aspects of biological processes, including cardiovascular biology. ${ }^{150}$ In addition to their role in cardiac development, ${ }^{151-153}$ miRNAs are also critically involved in the pathological process of adult hearts, both in humans and rodents, including cardiac hypertrophy, ${ }^{154-156}$ heart failure, ${ }^{157-159}$ cardiomyopathy, ${ }^{159}$ and arrhythmogenesis. ${ }^{160}$ Here we briefly touch on some of the miRNAs that have been implicated in $\mathrm{Ca}^{2+}$ signaling and EC coupling. For a more comprehensive understanding of the pivotal function of miRNA in cardiovascular pathologies, the reader is referred to more recent reviews on the subject. ${ }^{81,161,162}$ At this time, it is estimated that there are 150 to 200 miRNAs expressed in the cardiovascular system. For example, with respect to hypertrophy, multiple miRNAs, including the muscle-specific miRNAs (miR-1, miR-133, miR-208, and miR-499) and other miRNAs (miR-195, miR-21, and miR-18b), have been identified as participating in and can independently determine the pathological process. miR-195 was upregulated during cardiac hypertrophy, and its overexpression resulted in pathological cardiac growth and heart failure in transgenic mice. ${ }^{158}$ miR-133 was down-regulated in mouse and human models of cardiac hypertrophy. Although overexpression of miR-133 inhibited cardiac hypertrophy, ${ }^{163}$ suppression of miR-133 induced hypertrophy. ${ }^{154}$ In a separate study, miR-21 and miR-18b were shown to be antihypertrophic. ${ }^{155}$ miR-208a is upregulated in human hearts after myocardial infarction, ${ }^{164}$ and two-fold overexpression of miR-208 in mice is sufficient to promote cardiac hypertrophy and arrhythmia. ${ }^{165}$

However, despite these observations, contradictory miRNA data have been reported under comparable experimental conditions. For instance, using similar pressureoverload (TAC) mouse model of hypertrophy, miR-21 was reported to be highly upregulated 1 to 2 weeks post-TAC but decreased to a normal level after 3 to 4 weeks, ${ }^{156,166}$ whereas other studies reported a sustained expression over time. ${ }^{155,158}$ miR-1 was identified as being down-regulated or unchanged $^{156,166}$ in TAC models and upregulated in dilative cardiomyopathy and in patients with coronary artery disease, ${ }^{157,160}$ as well as in cardiomyocytes on oxidative stress. ${ }^{167}$ We have demonstrated that miR-1 is down-regulated in pressure overload-induced cardiac hypertrophy, and chronic restoration of miR-1 expression in vivo by adeno-associatedvirus 9-mediated gene transfer protected against the maladaptive cardiac remodeling induced by pressure overload. ${ }^{168}$ Clearly, differences in the published findings can be attributed to the different experimental models and protocols used, the extent of the disease progression, the developmental stage, and the times at which the measurements were made and the nature of pathological stresses applied. Recent studies have demonstrated that cardio-enriched miRNAs can be released into the circulation and could readily be detected in circulating blood. These circulating miRNAs may potentially constitute excellent candidate biomarkers for various diseases, including myocardial infarction and heart failure. ${ }^{169-171}$

With respect to $\mathrm{Ca}^{2+}$ signaling regulation, few microRNAs have been shown to directly or indirectly control $\mathrm{Ca}^{2+}$ cycling and regulate important targets involved in cardiomyocyte EC coupling. Manipulation of miR-1 has been shown to mediate $\mathrm{Ca}^{2+}$-dependent arrhythmogenesis through modulation of ion channels function and their associated regulators. For instance, overexpression of miR-1 in rat ventricular myocytes enhanced CaMKII-dependent phosphorylation of LTCC and RyR 2 by targeting protein phosphatase activity localized to the channels, leading to increased channel activity and disruption of $\mathrm{Ca}^{2+}$ cycling and promotion of arrhythmogenesis. ${ }^{172}$ Interestingly, similar effects were evoked by miR-133 overexpression. ${ }^{173}$ MiR-1 was also shown to modulate $\mathrm{Ca}^{2+}$ transients in cardiomyocytes by repressing sorcin expression in the heart failure model. ${ }^{174}$ This is important, since sorcin, as a $\mathrm{Ca}^{2+}$ modulator, is known to interact with and regulate several ionic channels, including LTCC, RyR2, NCX1, and SERCA2a, and thus plays an important role in the regulation of EC coupling. Moreover, miR-1 was also demonstrated to target and repress NCX1, a key regulator of $\mathrm{Ca}^{2+}$ influx, ${ }^{175,176}$ and annexin A5, ${ }^{176}$ further highlighting the pivotal role for miR-1 as a regulator of cardiomyocyte $\mathrm{Ca}^{2+}$ homeostasis. Interestingly, miR-214 was reported to target and repress NCX1 and protects cardiomyocytes from $\mathrm{Ca}^{2+}$-induced cell death during ischemia/reperfusion injury. ${ }^{177}$ In addition, miR-133a, which is bi-cistronically clustered with miR-1, was shown to have a strong effect on $\mathrm{Ca}^{2+}$ signaling pathways in cardiomyocytes by targeting calcineurin, ${ }^{178}$ NFATc4, ${ }^{179}$ and $\mathrm{IP}_{3} \mathrm{R} 2 .{ }^{180}$ The latter study also showed that $\mathrm{IP}_{3}$-induced $\mathrm{Ca}^{2+}$ release significantly contributes, in a feed-forward mechanism, to the down-regulation of miR-133a during hypertrophy and accentuation of pathological remodeling. ${ }^{180}$ In contrast, levels of miR-21 and miR-132, and miR328 were upregulated after isoproterenol stimulation and 
atrial fibrillation, respectively. ${ }^{181,182}$ miR-328 targeted and suppressed both the $\alpha 1 \mathrm{c}$ and $\beta 1$ subunits of the LTCC, whereas miR-21 and miR-132 both targeted $\beta 1$ subunits of the channel, which may explain the dramatic reduction in the L-type $\mathrm{Ca}^{2+}$ current and the subsequent alterations in EC coupling observed in these studies.

\section{Conclusion}

In heart physiology, $\mathrm{Ca}^{2+}$ is a double-edged sword for both life and death. Although it is required for proper cardiac maintenance, abnormalities in $\mathrm{Ca}^{2+}$ cycling and signaling are at the heart of contractile deficiency and the progression to cardiac hypertrophy and heart failure. Understanding the normal pathophysiology of myocardial $\mathrm{Ca}^{2+}$ signaling is important for devising adequate and appropriate strategies to correct $\mathrm{Ca}^{2+}$-stimulated maladaptive remodeling. Clinical trials targeting normalization of SR $\mathrm{Ca}^{2+}$ uptake (SERCA2a gene therapy) and reduction of SR $\mathrm{Ca}^{2+}$ leak (RyR stabilizers) are currently underway in patients with heart failure. Likewise, it is expected that new advances in myocardial $\mathrm{Ca}^{2+}$-dependent therapies will emerge in the near future, such as defining the sources of signaling $\mathrm{Ca}^{2+}$ and identifying pathological microRNAs involved in the induction of heart failure and arrhythmias.

\section{Disclosure}

The authors report no conflicts of interest in this work.

\section{References}

1. Marks AR. Calcium cycling proteins and heart failure: mechanisms and therapeutics. J Clin Invest. 2013;123(1):46-52.

2. van Berlo JH, Maillet M, Molkentin JD. Signaling effectors underlying pathologic growth and remodeling of the heart. J Clin Invest. 2013;123(1):37-45.

3. George AL Jr. Molecular and genetic basis of sudden cardiac death. $J$ Clin Invest. 2013;123(1):75-83.

4. Berridge MJ. Calcium microdomains: organization and function. Cell Calcium. 2006;40(5-6):405-412.

5. Cartwright EJ, Mohamed T, Oceandy D, Neyses L. Calcium signaling dysfunction in heart disease. Biofactors. 2011;37(3):175-181.

6. Goonasekera SA, Molkentin JD. Unraveling the secrets of a double life: contractile versus signaling $\mathrm{Ca} 2+$ in a cardiac myocyte. $J \mathrm{Mol}$ Cell Cardiol. 2012;52(2):317-322.

7. Bers DM. Calcium cycling and signaling in cardiac myocytes. Annu Rev Physiol. 2008;70:23-49.

8. Anderson ME. Ca2+-dependent regulation of cardiac L-type $\mathrm{Ca} 2+$ channels: is a unifying mechanism at hand? $J$ Mol Cell Cardiol. 2001;33(4):639-650.

9. Armoundas AA, Hobai IA, Tomaselli GF, Winslow RL, O’Rourke B. Role of sodium-calcium exchanger in modulating the action potential of ventricular myocytes from normal and failing hearts. Circ Res. 11, 2003;93(1):46-53.

10. Luo W, Grupp IL, Harrer J, et al. Targeted ablation of the phospholamban gene is associated with markedly enhanced myocardial contractility and loss of beta-agonist stimulation. Circ Res. 1994;75(3):401-409.
11. Koss KL, Kranias EG. Phospholamban: a prominent regulator of myocardial contractility. Circ Res. 1996;79(6):1059-1063.

12. del Monte F, Harding SE, Dec GW, Gwathmey JK, Hajjar RJ. Targeting phospholamban by gene transfer in human heart failure. Circulation. 2002;105(8):904-907.

13. Asahi M, Otsu K, Nakayama H, et al. Cardiac-specific overexpression of sarcolipin inhibits sarco(endo)plasmic reticulum $\mathrm{Ca} 2+$ ATPase (SERCA2a) activity and impairs cardiac function in mice. Proc Natl Acad Sci U S A. 2004;101(25):9199-9204.

14. Toyofuku T, Curotto Kurzydlowski K, Narayanan N, MacLennan DH. Identification of Ser38 as the site in cardiac sarcoplasmic reticulum $\mathrm{Ca}(2+)$-ATPase that is phosphorylated by $\mathrm{Ca} 2+/$ calmodulin-dependent protein kinase. J Biol Chem. 1994;269(42):26492-26496.

15. Narayanan $\mathrm{N}, \mathrm{Xu} \mathrm{A}$. Phosphorylation and regulation of the $\mathrm{Ca}(2+)-$ pumping ATPase in cardiac sarcoplasmic reticulum by calcium/calmodulin-dependent protein kinase. Basic Res Cardiol. 1997;92 Suppl 1: 25-35.

16. Molkentin JD. Dichotomy of $\mathrm{Ca} 2+$ in the heart: contraction versus intracellular signaling. J Clin Invest. 2006;116(3):623-626.

17. Bito V, Heinzel FR, Biesmans L, Antoons G, Sipido KR. Crosstalk between L-type $\mathrm{Ca} 2+$ channels and the sarcoplasmic reticulum: alterations during cardiac remodelling. Cardiovasc Res. 2008;77(2): 315-324.

18. Franzini-Armstrong C. Architecture and regulation of the $\mathrm{Ca} 2+$ delivery system in muscle cells. Appl Physiol Nutr Metab. 2009;34(3): 323-327.

19. García-Pérez C, Hajnóczky G, Csordás G. Physical coupling supports the local $\mathrm{Ca} 2+$ transfer between sarcoplasmic reticulum subdomains and the mitochondria in heart muscle. J Biol Chem. 2008;283(47): 32771-32780.

20. Kohlhaas M, Mack C. Calcium release microdomains and mitochondria. Cardiovasc Res. 2013;98(2):259-268.

21. Balijepalli RC, Foell JD, Hall DD, Hell JW, Kamp TJ. Localization of cardiac L-type $\mathrm{Ca}(2+)$ channels to a caveolar macromolecular signaling complex is required for beta(2)-adrenergic regulation. Proc Natl Acad Sci U S A. 2006;103(19):7500-7505.

22. Tandan S, Wang Y, Wang TT, et al. Physical and functional interaction between calcineurin and the cardiac L-type Ca2+ channel. Circ Res. 2009;105(1):51-60.

23. Markandeya YS, Fahey JM, Pluteanu F, Cribbs LL, Balijepalli RC. Caveolin-3 regulates protein kinase A modulation of the $\mathrm{Ca}(\mathrm{V}) 3.2($ alpha1H) T-type Ca2+ channels. J Biol Chem. 2011;286(4):2433-2444.

24. Fujimoto T. Calcium pump of the plasma membrane is localized in caveolae. J Cell Biol. 1993;120(5):1147-1157.

25. Wu X, Chang B, Blair NS, et al. Plasma membrane Ca2+-ATPase isoform 4 antagonizes cardiac hypertrophy in association with calcineurin inhibition in rodents. J Clin Invest. 2009;119(4):976-985.

26. Cartwright EJ, Oceandy D, Neyses L. Physiological implications of the interaction between the plasma membrane calcium pump and nNOS Pflugers Arch. 2009;457(3):665-671.

27. Eder P, Molkentin JD. TRPC channels as effectors of cardiac hypertrophy. Circ Res. 2011;108(2):265-272.

28. Bush EW, Hood DB, Papst PJ, et al. Canonical transient receptor potential channels promote cardiomyocyte hypertrophy through activation of calcineurin signaling. J Biol Chem. 2006;281(44):33487-33496.

29. Higazi DR, Fearnley CJ, Drawnel FM, et al. Endothelin-1-stimulated InsP3-induced $\mathrm{Ca} 2+$ release is a nexus for hypertrophic signaling in cardiac myocytes. Mol Cell. 2009;33(4):472-482.

30. Nakayama H, Bodi I, Maillet M, et al. The IP3 receptor regulates cardiac hypertrophy in response to select stimuli. Circ Res. 2010;107(5): 659-666.

31. Roos J, DiGregorio PJ, Yeromin AV, et al. STIM1, an essential and conserved component of store-operated $\mathrm{Ca} 2+$ channel function. $J$ Cell Biol. 2005;169(3):435-445.

32. Liou J, Kim ML, Heo WD, et al. STIM is a Ca2+ sensor essential for Ca2+-store-depletion-triggered Ca2+ influx. Curr Biol. 2005;15(13): 1235-1241. 
33. Williams RT, Manji SS, Parker NJ, et al. Identification and characterization of the STIM (stromal interaction molecule) gene family: coding for a novel class of transmembrane proteins. Biochem J. 2001;357(Pt 3):673-685.

34. Lewis RS. The molecular choreography of a store-operated calcium channel. Nature. 2007;446(7133):284-287.

35. Putney JW Jr. Recent breakthroughs in the molecular mechanism of capacitative calcium entry (with thoughts on how we got here). Cell Calcium. 2007;42(2):103-110.

36. Feske S, Gwack Y, Prakriya M, et al. A mutation in Orail causes immune deficiency by abrogating CRAC channel function. Nature. 2006;441(7090):179-185

37. Vig M, Peinelt C, Beck A, et al. CRACM1 is a plasma membrane protein essential for store-operated $\mathrm{Ca} 2+$ entry. Science. 2006;312(5777):1220-1223.

38. Zhang SL, Yeromin AV, Zhang XH, et al. Genome-wide RNAi screen of $\mathrm{Ca}(2+)$ influx identifies genes that regulate $\mathrm{Ca}(2+)$ release-activated $\mathrm{Ca}(2+)$ channel activity. Proc Natl Acad Sci U S A. 2006;103(24): 9357-9362.

39. Cahalan MD. STIMulating store-operated $\mathrm{Ca}(2+)$ entry. Nat Cell Biol. 2009;11(6):669-677.

40. Soboloff J, Rothberg BS, Madesh M, Gill DL. STIM proteins: dynamic calcium signal transducers. Nat Rev Mol Cell Biol. 2012;13(9): 549-565.

41. Zweifach A, Lewis RS. Rapid inactivation of depletion-activated calcium current (ICRAC) due to local calcium feedback. J Gen Physiol. 1995;105(2):209-226.

42. Lee KP, Yuan JP, Zeng W, So I, Worley PF, Muallem S. Molecular determinants of fast $\mathrm{Ca} 2+$-dependent inactivation and gating of the Orai channels. Proc Natl Acad Sci U S A. 2009;106(34): 14687-14692.

43. Litjens T, Harland ML, Roberts ML, Barritt GJ, Rychkov GY. Fast $\mathrm{Ca}(2+)$-dependent inactivation of the store-operated $\mathrm{Ca} 2+$ current (ISOC) in liver cells: a role for calmodulin. J Physiol. 2004;558(Pt 1): 85-97.

44. Shen WW, Frieden M, Demaurex N. Local cytosolic Ca2+ elevations are required for stromal interaction molecule 1 (STIM1) deoligomerization and termination of store-operated Ca2+ entry. J Biol Chem. 2011;286(42):36448-36459.

45. Hunton DL, Lucchesi PA, Pang Y, Cheng X, Dell'Italia LJ, Marchase RB. Capacitative calcium entry contributes to nuclear factor of activated T-cells nuclear translocation and hypertrophy in cardiomyocytes. J Biol Chem. 2002;277(16):14266-14273.

46. Uehara A, Yasukochi M, Imanaga I, Nishi M, Takeshima H. Storeoperated $\mathrm{Ca} 2+$ entry uncoupled with ryanodine receptor and junctional membrane complex in heart muscle cells. Cell Calcium. 2002;31(2): 89-96.

47. Voelkers M, Salz M, Herzog N, et al. Orail and Stim1 regulate normal and hypertrophic growth in cardiomyocytes. $\mathrm{J} \mathrm{Mol} \mathrm{Cell} \mathrm{Cardiol.}$ 2010;48(6):1329-1334.

48. Hulot JS, Fauconnier J, Ramanujam D, et al. Critical role for stromal interaction molecule 1 in cardiac hypertrophy. Circulation. 2011;124(7): 796-805.

49. Luo X, Hojayev B, Jiang N, et al. STIM1-dependent store-operated $\mathrm{Ca}^{2+}$ entry is required for pathological cardiac hypertrophy. J Mol Cell Cardiol. 2012;52(1):136-147.

50. Soboloff J, Spassova MA, Tang XD, Hewavitharana T, Xu W, Gill DL. Orail and STIM reconstitute store-operated calcium channel function. J Biol Chem. 28, 2006;281(30):20661-20665.

51. Prakriya M, Feske S, Gwack Y, Srikanth S, Rao A, Hogan PG. Orai1 is an essential pore subunit of the CRAC channel. Nature. 2006;443(7108): 230-233.

52. Yuan JP, Kim MS, Zeng W, et al. TRPC channels as STIM1-regulated SOCs. Channels (Austin). 2009;3(4):221-225.

53. Pani B, Bollimuntha $\mathrm{S}$, Singh BB. The TR (i) $\mathrm{P}_{\text {to }} \mathrm{Ca}^{2+}$ signaling just got STIMy: an update on STIM1 activated TRPC channels. Front Biosci. 2012; $17: 805-823$.
54. Nakayama H, Wilkin BJ, Bodi I, Molkentin JD. Calcineurin-dependent cardiomyopathy is activated by TRPC in the adult mouse heart. FASEB J. 2006;20(10):1660-1670.

55. Ohba T, Watanabe H, Murakami M, et al. Upregulation of TRPC 1 in the development of cardiac hypertrophy. J Mol Cell Cardiol. 2007;42(3): 498-507.

56. Seth M, Zhang ZS, Mao L, et al. TRPC1 channels are critical for hypertrophic signaling in the heart. Circ Res. 2009;105(10):1023-1030.

57. Kuwahara K, Wang Y, McAnally J, et al. TRPC6 fulfills a calcineurin signaling circuit during pathologic cardiac remodeling. J Clin Invest. 2006;116(12):3114-3126.

58. Onohara N, Nishida M, Inoue R, et al. TRPC3 and TRPC6 are essential for angiotensin II-induced cardiac hypertrophy. EMBOJ. 2006;25(22): $5305-5316$.

59. Wang Y, Deng X, Mancarella S, et al. The calcium store sensor, STIM1, reciprocally controls Orai and CaV1.2 channels. Science. 2010;330(6000):105-109.

60. Park CY, Shcheglovitov A, Dolmetsch R. The CRAC channel activator STIM1 binds and inhibits L-type voltage-gated calcium channels. Science. 2010;330(6000):101-105.

61. MacLennan DH, Kranias EG. Phospholamban: a crucial regulator of cardiac contractility. Nat Rev Mol Cell Biol. 2003;4(7):566-577.

62. Miyamoto MI, del Monte F, Schmidt U, et al. Adenoviral gene transfer of SERCA2a improves left-ventricular function in aortic-banded rats in transition to heart failure. Proc Natl Acad Sci U S A. 2000;97(2): 793-798.

63. del Monte F, Williams E, Lebeche D, et al. Improvement in survival and cardiac metabolism after gene transfer of sarcoplasmic reticulum $\mathrm{Ca}(2+)$-ATPase in a rat model of heart failure. Circulation. 2001;104(12):1424-1429.

64. Hajjar RJ, Schmidt U, Kang JX, Matsui T, Rosenzweig A. Adenoviral gene transfer of phospholamban in isolated rat cardiomyocytes. Rescue effects by concomitant gene transfer of sarcoplasmic reticulum $\mathrm{Ca}(2+)$ ATPase. Circ Res. 1997;81(2):145-153.

65. del Monte F, Harding SE, Schmidt U, et al. Restoration of contractile function in isolated cardiomyocytes from failing human hearts by gene transfer of SERCA2a. Circulation. 1999;100(23):2308-2311.

66. Lyon AR, Bannister ML, Collins T, et al. SERCA2a gene transfer decreases sarcoplasmic reticulum calcium leak and reduces ventricular arrhythmias in a model of chronic heart failure. Circ Arrhythm Electrophysiol. 2011;4(3):362-372.

67. Hajjar RJ. Potential of gene therapy as a treatment for heart failure. J Clin Invest. 2013;123(1):53-61.

68. Hajjar RJ, Zsebo K, Deckelbaum L, et al. Design of a phase 1/2 trial of intracoronary administration of AAV1/SERCA2a in patients with heart failure. J Card Fail. 2008;14(5):355-367.

69. Jaski BE, Jessup ML, Mancini DM, et al; Calcium Up-Regulation by Percutaneous Administration of Gene Therapy In Cardiac Disease (CUPID) Trial Investigators. Calcium upregulation by percutaneous administration of gene therapy in cardiac disease (CUPID Trial), a first-in-human phase 1/2 clinical trial. $J$ Card Fail. 2009;15(3): 171-181.

70. O'Rourke B, Kass DA, Tomaselli GF, Kääb S, Tunin R, Marbán E. Mechanisms of altered excitation-contraction coupling in canine tachycardia-induced heart failure, I: experimental studies. Circ Res. 1999;84(5):562-570.

71. Flesch M, Schwinger RH, Schiffer F, et al. Evidence for functional relevance of an enhanced expression of the $\mathrm{Na}(+)-\mathrm{Ca} 2+$ exchanger in failing human myocardium. Circulation. 1996;94(5):992-1002.

72. Houser SR, Margulies KB. Is depressed myocyte contractility centrally involved in heart failure? Circ Res. 2003;92(4):350-358.

73. Marx SO, Reiken S, Hisamatsu Y, et al. PKA phosphorylation dissociates FKBP12.6 from the calcium release channel (ryanodine receptor): defective regulation in failing hearts. Cell. 2000;101(4):365-376.

74. Shan J, Betzenhauser MJ, Kushnir A, et al. Role of chronic ryanodine receptor phosphorylation in heart failure and $\beta$-adrenergic receptor blockade in mice. $J$ Clin Invest. 2010;120(12):4375-4387. 
75. Wehrens XH, Lehnart SE, Reiken SR, Marks AR. Ca2+/calmodulindependent protein kinase II phosphorylation regulates the cardiac ryanodine receptor. Circ Res. 2004;94(6):e61-e70.

76. Bers DM. Macromolecular complexes regulating cardiac ryanodine receptor function. J Mol Cell Cardiol. 2004;37(2):417-429.

77. Blayney LM, Lai FA. Ryanodine receptor-mediated arrhythmias and sudden cardiac death. Pharmacol Ther. 2009;123(2):151-177.

78. Jiang MT, Lokuta AJ, Farrell EF, Wolff MR, Haworth RA, Valdivia HH. Abnormal $\mathrm{Ca} 2+$ release, but normal ryanodine receptors, in canine and human heart failure. Circ Res. 2002;91(11):1015-1022.

79. Xiao J, Tian X, Jones PP, et al. Removal of FKBP12.6 does not alter the conductance and activation of the cardiac ryanodine receptor or the susceptibility to stress-induced ventricular arrhythmias. J Biol Chem. 2007;282(48):34828-34838.

80. Guo T, Cornea RL, Huke S, et al. Kinetics of FKBP12.6 binding to ryanodine receptors in permeabilized cardiac myocytes and effects on Ca sparks. Circ Res. 2010;106(11):1743-1752.

81. Abdellatif M. Differential expression of microRNAs in different disease states. Circ Res. 2012;110(4):638-650.

82. Domeier TL, Zima AV, Maxwell JT, Huke S, Mignery GA, Blatter LA IP3 receptor-dependent $\mathrm{Ca} 2+$ release modulates excitation-contraction coupling in rabbit ventricular myocytes. Am J Physiol Heart Circ Physiol. 2008;294(2):H596-H604.

83. Wu X, Zhang T, Bossuyt J, et al. Local InsP3-dependent perinuclear $\mathrm{Ca} 2+$ signaling in cardiac myocyte excitation-transcription coupling. J Clin Invest. 2006;116(3):675-682.

84. Kockskämper J, Zima AV, Roderick HL, Pieske B, Blatter LA, Bootman MD. Emerging roles of inositol 1,4,5-trisphosphate signaling in cardiac myocytes. J Mol Cell Cardiol. 2008;45(2):128-147.

85. Harzheim D, Movassagh M, Foo RS, et al. Increased InsP3Rs in the junctional sarcoplasmic reticulum augment $\mathrm{Ca} 2+$ transients and arrhythmias associated with cardiac hypertrophy. Proc Natl Acad Sci US A. 2009;106(27):11406-11411.

86. Harzheim D, Talasila A, Movassagh M, et al. Elevated InsP3R expression underlies enhanced calcium fluxes and spontaneous extra-systolic calcium release events in hypertrophic cardiac myocytes. Channels (Austin). 2010;4(1):67-71.

87. Luo DL, Gao J, Lan XM, et al. Role of inositol 1,4,5-trisphosphate receptors in alpha1-adrenergic receptor-induced cardiomyocyte hypertrophy. Acta Pharmacol Sin. 2006;27(7): 895-900.

88. Watanabe H, Murakami M, Ohba T, Ono K, Ito H. The pathological role of transient receptor potential channels in heart disease. Circ J. 2009;73(3):419-427.

89. Lockwich TP, Liu X, Singh BB, Jadlowiec J, Weiland S, Ambudkar IS. Assembly of Trp1 in a signaling complex associated with caveolin-scaffolding lipid raft domains. J Biol Chem. 2000;275(16): 11934-11942.

90. Brazer SC, Singh BB, Liu X, Swaim W, Ambudkar IS. Caveolin-1 contributes to assembly of store-operated $\mathrm{Ca} 2+$ influx channels by regulating plasma membrane localization of TRPC1. J Biol Chem. 2003;278(29):27208-27215.

91. Lavender V, Chong S, Ralphs K, Wolstenholme AJ, Reaves BJ. Increasing the expression of calcium-permeable TRPC3 and TRPC7 channels enhances constitutive secretion. Biochem J. 2008;413(3):437-446.

92. Berbey C, Weiss N, Legrand C, Allard B. Transient receptor potential canonical type 1 (TRPC1) operates as a sarcoplasmic reticulum calcium leak channel in skeletal muscle. J Biol Chem. 2009;284(52):36387-36394

93. Wu X, Eder P, Chang B, Molkentin JD. TRPC channels are necessary mediators of pathologic cardiac hypertrophy. Proc Natl Acad Sci USA. 2010;107(15):7000-7005.

94. Brenner JS, Dolmetsch RE. TrpC3 regulates hypertrophy-associated gene expression without affecting myocyte beating or cell size. PLoS One. 2007;2(8):e802.

95. Kiyonaka S, Kato K, Nishida M, et al. Selective and direct inhibition of TRPC3 channels underlies biological activities of a pyrazole compound. Proc Natl Acad Sci U S A. 2009;106(13):5400-5405.
96. Kinoshita H, Kuwahara K, Nishida M, et al. Inhibition of TRPC6 channel activity contributes to the antihypertrophic effects of natriuretic peptides-guanylyl cyclase-A signaling in the heart. Circ Res. 2010;106(12):1849-1860.

97. Satoh S, Tanaka H, Ueda Y, et al. Transient receptor potential (TRP) protein 7 acts as a $\mathrm{G}$ protein-activated $\mathrm{Ca} 2+$ channel mediating angiotensin II-induced myocardial apoptosis. Mol Cell Biochem. 2007;294(1-2):205-215.

98. Shan D, Marchase RB, Chatham JC. Overexpression of TRPC3 increases apoptosis but not necrosis in response to ischemiareperfusion in adult mouse cardiomyocytes. Am J Physiol Cell Physiol. 2008;294(3):C833-C841.

99. Heineke J, Auger-Messier M, Correll RN, et al. CIB1 is a regulator of pathological cardiac hypertrophy. Nat Med. 2010;16(8): 872-879.

100. Bos JL. Epac: a new cAMP target and new avenues in cAMP research. Nat Rev Mol Cell Biol. 2003;4(9):733-738.

101. Morel E, Marcantoni A, Gastineau M, et al. cAMP-binding protein Epac induces cardiomyocyte hypertrophy. Circ Res. 2005;97(12): 1296-1304.

102. Oestreich EA, Wang H, Malik S, et al. Epac-mediated activation of phospholipase $\mathrm{C}$ (epsilon) plays a critical role in beta-adrenergic receptor-dependent enhancement of $\mathrm{Ca} 2+$ mobilization in cardiac myocytes. J Biol Chem. 2007;282(8):5488-5495.

103. Pereira L, Métrich M, Fernández-Velasco M, et al. The cAMP binding protein Epac modulates $\mathrm{Ca} 2+$ sparks by a $\mathrm{Ca} 2+$ /calmodulin kinase signalling pathway in rat cardiac myocytes. J Physiol. 2007;583(Pt 2): 685-694.

104. Oestreich EA, Malik S, Goonasekera SA, et al. Epac and phospholipase Cepsilon regulate $\mathrm{Ca} 2+$ release in the heart by activation of protein kinase Cepsilon and calcium-calmodulin kinase II. J Biol Chem. 2009;284(3):1514-1522.

105. Pereira L, Ruiz-Hurtado G, Morel E, et al. Epac enhances excitationtranscription coupling in cardiac myocytes. J Mol Cell Cardiol. 2012;52(1):283-291.

106. Hothi SS, Gurung IS, Heathcote JC, et al. Epac activation, altered calcium homeostasis and ventricular arrhythmogenesis in the murine heart. Pflugers Arch. 2008;457(2):253-270.

107. Curran J, Hinton MJ, Ríos E, Bers DM, Shannon TR. Beta-adrenergic enhancement of sarcoplasmic reticulum calcium leak in cardiac myocytes is mediated by calcium/calmodulin-dependent protein kinase. Circ Res. 2007;100(3):391-398

108. Ogrodnik J, Niggli E. Increased $\mathrm{Ca}(2+)$ leak and spatiotemporal coherence of $\mathrm{Ca}(2+)$ release in cardiomyocytes during beta-adrenergic stimulation. J Physiol. 2010;588(Pt 1):225-242.

109. Pereira L, Cheng H, Lao DH, et al. Epac2 mediates cardiac $\beta 1$-adrenergic-dependent sarcoplasmic reticulum $\mathrm{Ca} 2+$ leak and arrhythmia. Circulation. 2013;127(8):913-922.

110. Métrich M, Lucas A, Gastineau M, et al. Epac mediates betaadrenergic receptor-induced cardiomyocyte hypertrophy. Circ Res. 2008;102(8):959-965.

111. Ulucan C, Wang X, Baljinnyam E, et al. Developmental changes in gene expression of Epac and its upregulation in myocardial hypertrophy. Am J Physiol Heart Circ Physiol. 2007;293(3):H1662-H1672.

112. Ruiz-Hurtado G, Morel E, Domínguez-Rodríguez A, et al. Epac in cardiac calcium signaling. J Mol Cell Cardiol. 2013;58:162-171.

113. Métrich M, Laurent AC, Breckler M, et al. Epac activation induces histone deacetylase nuclear export via a Ras-dependent signalling pathway. Cell Signal. 2010;22(10):1459-1468.

114. Wickenden AD, Kaprielian R, Kassiri Z, et al. The role of action potential prolongation and altered intracellular calcium handling in the pathogenesis of heart failure. Cardiovasc Res. 1998;37(2): 312-323.

115. Kääb S, Dixon J, Duc J, et al. Molecular basis of transient outward potassium current downregulation in human heart failure: a decrease in Kv4.3 mRNA correlates with a reduction in current density. Circulation. 1998;98(14):1383-1393. 
116. Huang B, Qin D, El-Sherif N. Early down-regulation of K+ channel genes and currents in the postinfarction heart. J Cardiovasc Electrophysiol. 2000;11(11):1252-1261.

117. Bailly P, Bénitah JP, Mouchonière M, Vassort G, Lorente P. Regional alteration of the transient outward current in human left ventricular septum during compensated hypertrophy. Circulation. 1997;96(4):1266-1274.

118. Beuckelmann DJ, Näbauer M, Erdmann E. Alterations of K+ currents in isolated human ventricular myocytes from patients with terminal heart failure. Circ Res. 1993;73(2):379-385.

119. Tomaselli GF, Marbán E. Electrophysiological remodeling in hypertrophy and heart failure. Cardiovasc Res. 1999;42(2):270-283.

120. Kaprielian R, Wickenden AD, Kassiri Z, Parker TG, Liu PP, Backx PH. Relationship between $\mathrm{K}+$ channel down-regulation and $[\mathrm{Ca} 2+] \mathrm{i}$ in rat ventricular myocytes following myocardial infarction. J Physiol. 1999;517(Pt 1):229-245.

121. Takimoto K, Li D, Hershman KM, Li P, Jackson EK, Levitan ES. Decreased expression of Kv4.2 and novel Kv4.3 K+ channel subunit mRNAs in ventricles of renovascular hypertensive rats. Circ Res. 1997;81(4):533-539.

122. Bouchard RA, Clark RB, Giles WR. Effects of action potential duration on excitation-contraction coupling in rat ventricular myocytes. Action potential voltage-clamp measurements. Circ Res. 1995;76(5): 790-801

123. Barry DM, Xu H, Schuessler RB, Nerbonne JM. Functional knockout of the transient outward current, long-QT syndrome, and cardiac remodeling in mice expressing a dominant-negative Kv4 alpha subunit. Circ Res. 1998;83(5):560-567.

124. Wickenden AD, Lee P, Sah R, Huang Q, Fishman GI, Backx PH. Targeted expression of a dominant-negative $\mathrm{K}(\mathrm{v}) 4.2 \mathrm{~K}(+)$ channel subunit in the mouse heart. Circ Res. 1999;85(11):1067-1076.

125. Qin D, Zhang ZH, Caref EB, Boutjdir M, Jain P, el-Sherif N. Cellular and ionic basis of arrhythmias in postinfarction remodeled ventricular myocardium. Circ Res. 1996;79(3):461-473.

126. Nuss HB, Kääb S, Kass DA, Tomaselli GF, Marbán E. Cellular basis of ventricular arrhythmias and abnormal automaticity in heart failure. Am J Physiol. 1999;277(1 Pt 2):H80-H91.

127. Tomaselli GF, Beuckelmann DJ, Calkins HG, et al. Sudden cardiac death in heart failure. The role of abnormal repolarization. Circulation. 1994;90(5):2534-2539.

128. Puglisi JL, Yuan W, Bassani JW, Bers DM. Ca(2+) influx through $\mathrm{Ca}(2+)$ channels in rabbit ventricular myocytes during action potential clamp: influence of temperature. Circ Res. 1999;85(6):e7-e16.

129. Volk T, Nguyen TH, Schultz JH, Ehmke H. Relationship between transient outward $\mathrm{K}+$ current and $\mathrm{Ca} 2+$ influx in rat cardiac myocytes of endo- and epicardial origin. J Physiol. 1999;519(Pt 3):841-850.

130. Lebeche D, Kaprielian R, Hajjar R. Modulation of action potential duration on myocyte hypertrophic pathways. J Mol Cell Cardiol. 2006;40(5):725-735.

131. Lebeche D, Kaprielian R, del Monte F, et al. In vivo cardiac gene transfer of Kv4.3 abrogates the hypertrophic response in rats after aortic stenosis. Circulation. 2004;110(22):3435-3443.

132. Jin H, Hadri L, Palomeque J, et al. KChIP2 attenuates cardiac hypertrophy through regulation of Ito and intracellular calcium signaling. J Mol Cell Cardiol. 2010;48(6):1169-1179.

133. Ter Keurs HE, Boyden PA. Calcium and arrhythmogenesis. Physiol Rev. 2007;87(2):457-506.

134. Thomas NL, George CH, Lai FA. Role of ryanodine receptor mutations in cardiac pathology: more questions than answers? Biochem Soc Trans. 2006;34(Pt 5):913-918.

135. Wehrens XH, Lehnart SE, Huang F, et al. FKBP12.6 deficiency and defective calcium release channel (ryanodine receptor) function linked to exercise-induced sudden cardiac death. Cell. 2003;113(7): 829-840.

136. Lehnart SE, Wehrens XH, Marks AR. Calstabin deficiency, ryanodine receptors, and sudden cardiac death. Biochem Biophys Res Commun. 2004;322(4):1267-1279.
137. Clusin WT. Calcium and cardiac arrhythmias: DADs, EADs, and alternans. Crit Rev Clin Lab Sci. 2003;40(3):337-375.

138. Janse MJ. Electrophysiological changes in heart failure and their relationship to arrhythmogenesis. Cardiovasc Res. 2004;61(2):208-217.

139. Weiss JN, Nivala M, Garfinkel A, Qu Z. Alternans and arrhythmias: from cell to heart. Circ Res. 2011;108(1):98-112.

140. Laurita KR, Rosenbaum DS. Cellular mechanisms of arrhythmogenic cardiac alternans. Prog Biophys Mol Biol. 2008;97(2-3):332-347.

141. del Monte F, Lebeche D, Guerrero JL, et al. Abrogation of ventricular arrhythmias in a model of ischemia and reperfusion by targeting myocardial calcium cycling. Proc Natl Acad Sci USA. 2004;101(15): 5622-5627.

142. Hajjar RJ, Kang JX, Gwathmey JK, Rosenzweig A. Physiological effects of adenoviral gene transfer of sarcoplasmic reticulum calcium ATPase in isolated rat myocytes. Circulation. 1997;95(2):423-429.

143. Sakata S, Lebeche D, Sakata Y, et al. Mechanical and metabolic rescue in a type II diabetes model of cardiomyopathy by targeted gene transfer. Mol Ther. 2006;13(5):987-996.

144. Cutler MJ, Wan X, Plummer BN, et al. Targeted sarcoplasmic reticulum $\mathrm{Ca} 2+$ ATPase $2 \mathrm{a}$ gene delivery to restore electrical stability in the failing heart. Circulation. 2012;126(17):2095-2104

145. Cross HR, Murphy E, Bolli R, Ping P, Steenbergen C. Expression of activated PKC epsilon (PKC epsilon) protects the ischemic heart, without attenuating ischemic $\mathrm{H}(+)$ production. $J$ Mol Cell Cardiol. 2002;34(3):361-367.

146. Yue Y, Qu Y, Boutjdir M. Protective role of protein kinase C epsilon activation in ischemia-reperfusion arrhythmia. Biochem Biophys Res Commun. 2006;349(1):432-438.

147. Bers DM, Eisner DA, Valdivia HH. Sarcoplasmic reticulum Ca2+ and heart failure: roles of diastolic leak and $\mathrm{Ca} 2+$ transport. Circ Res. 2003;93(6):487-490.

148. Picht E, DeSantiago J, Huke S, Kaetzel MA, Dedman JR, Bers DM. CaMKII inhibition targeted to the sarcoplasmic reticulum inhibits frequency-dependent acceleration of relaxation and $\mathrm{Ca} 2+$ current facilitation. J Mol Cell Cardiol. 2007;42(1):196-205.

149. Khoo MS, Li J, Singh MV, et al. Death, cardiac dysfunction, and arrhythmias are increased by calmodulin kinase II in calcineurin cardiomyopathy. Circulation. 2006;114(13):1352-1359.

150. Bartel DP. MicroRNAs: genomics, biogenesis, mechanism, and function. Cell. 2004;116(2):281-297.

151. Zhao Y, Samal E, Srivastava D. Serum response factor regulates a muscle-specific microRNA that targets Hand2 during cardiogenesis. Nature. 2005;436(7048):214-220.

152. Callis TE, Chen JF, Wang DZ. MicroRNAs in skeletal and cardiac muscle development. DNA Cell Biol. 2007;26(4):219-225.

153. Zhao Y, Ransom JF, Li A, et al. Dysregulation of cardiogenesis, cardiac conduction, and cell cycle in mice lacking miRNA-1-2. Cell. 2007;129(2):303-317.

154. Carè A, Catalucci D, Felicetti F, et al. MicroRNA-133 controls cardiac hypertrophy. Nat Med. 2007;13(5):613-618.

155. Sayed D, Hong C, Chen IY, Lypowy J, Abdellatif M. MicroRNAs play an essential role in the development of cardiac hypertrophy. Circ Res. 2007;100(3):416-424

156. Tatsuguchi M, Seok HY, Callis TE, et al. Expression of microRNAs is dynamically regulated during cardiomyocyte hypertrophy. $\mathrm{J} \mathrm{Mol}$ Cell Cardiol. 2007;42(6):1137-1141.

157. Thum T, Galuppo P, Wolf C, et al. MicroRNAs in the human heart: a clue to fetal gene reprogramming in heart failure. Circulation. 2007;116(3):258-267.

158. van Rooij E, Sutherland LB, Liu N, et al. A signature pattern of stressresponsive microRNAs that can evoke cardiac hypertrophy and heart failure. Proc Natl Acad Sci U S A. 2006;103(48):18255-18260.

159. Ikeda S, Kong SW, Lu J, et al. Altered microRNA expression in human heart disease. Physiol Genomics. 2007;31(3):367-373.

160. Yang B, Lin H, Xiao J, et al. The muscle-specific microRNA miR-1 regulates cardiac arrhythmogenic potential by targeting GJA1 and KCNJ2. Nat Med. 2007;13(4):486-491. 
161. Small EM, Olson EN. Pervasive roles of microRNAs in cardiovascular biology. Nature. 2011;469(7330):336-342.

162. Quiat D, Olson EN. MicroRNAs in cardiovascular disease: from pathogenesis to prevention and treatment. J Clin Invest. 2013;123(1): $11-18$.

163. Matkovich SJ, Wang W, Tu Y, et al. MicroRNA-133a protects against myocardial fibrosis and modulates electrical repolarization without affecting hypertrophy in pressure-overloaded adult hearts. Circ Res. 2010;106(1):166-175.

164. Bostjancic E, Zidar N, Stajer D, Glavac D. MicroRNAs miR-1, miR133a, miR-133b and miR-208 are dysregulated in human myocardial infarction. Cardiology. 2010;1115(3):163-169.

165. Callis TE, Pandya K, Seok HY, et al. MicroRNA-208a is a regulator of cardiac hypertrophy and conduction in mice. $J$ Clin Invest. 2009;119(9):2772-2786.

166. Luo D, Yang D, Lan X, et al. Nuclear Ca2+ sparks and waves mediated by inositol 1,4,5-trisphosphate receptors in neonatal rat cardiomyocytes. Cell Calcium. 2008;43(2):165-174.

167. Xu C, Lu Y, Pan Z, et al. The muscle-specific microRNAs miR-1 and miR-133 produce opposing effects on apoptosis by targeting HSP60, HSP70 and caspase-9 in cardiomyocytes. J Cell Sci. 2007;120(Pt 17): 3045-3052.

168. Karakikes I, Chaanine AH, Kang S, et al. Therapeutic cardiac-targeted delivery of miR-1 reverses pressure overload-induced cardiac hypertrophy and attenuates pathological remodeling. J Am Heart Assoc. 2013;2(2):e000078.

169. Dimmeler S, Zeiher AM. Circulating microRNAs: novel biomarkers for cardiovascular diseases? Eur Heart J. 2010;31(22):2705-2707.

170. Gupta SK, Bang C, Thum T. Circulating microRNAs as biomarkers and potential paracrine mediators of cardiovascular disease. Circ Cardiovasc Genet. 2010;3(5):484-488.

171. Goren Y, Kushnir M, Zafrir B, Tabak S, Lewis BS, Amir O. Serum levels of microRNAs in patients with heart failure. Eur J Heart Fail. 2012;14(2):147-154.

172. Terentyev D, Belevych AE, Terentyeva R, et al. miR-1 overexpression enhances $\mathrm{Ca}(2+)$ release and promotes cardiac arrhythmogenesis by targeting PP2A regulatory subunit B56alpha and causing CaMKIIdependent hyperphosphorylation of RyR2. Circ Res. 2009;104(4): 514-521.
173. Belevych AE, Sansom SE, Terentyeva R, et al. MicroRNA-1 and -133 increase arrhythmogenesis in heart failure by dissociating phosphatase activity from RyR2 complex. PLoS One. 2016(12):e28324.

174. Ali R, Huang Y, Maher SE, et al. miR-1 mediated suppression of Sorcin regulates myocardial contractility through modulation of Ca2+ signaling. J Mol Cell Cardiol. 2012;52(5):1027-1037.

175. Kumarswamy R, Lyon AR, Volkmann I, et al. SERCA2a gene therapy restores microRNA-1 expression in heart failure via an Akt/FoxO3Adependent pathway. Eur Heart J. 2012;33(9):1067-1075.

176. Tritsch E, Mallat Y, Lefebvre F, et al. An SRF/miR-1 axis regulates NCX1 and Annexin A5 protein levels in the normal and failing heart. Cardiovasc Res. 2013;98(3):372-380.

177. Aurora AB, Mahmoud AI, Luo X, et al. MicroRNA-214 protects the mouse heart from ischemic injury by controlling $\mathrm{Ca}^{2+}$ overload and cell death. J Clin Invest. 2012;122(4):1222-1232.

178. Dong DL, Chen C, Huo R, et al. Reciprocal repression between microRNA-133 and calcineurin regulates cardiac hypertrophy: a novel mechanism for progressive cardiac hypertrophy. Hypertension. 2010;55(4):946-952.

179. Li Q, Lin X, Yang X, Chang J. NFATc4 is negatively regulated in miR-133a-mediated cardiomyocyte hypertrophic repression. Am J Physiol Heart Circ Physiol. 2010;298(5):H1340-H1347.

180. Drawnel FM, Wachten D, Molkentin JD, et al. Mutual antagonism between IP(3)RII and miRNA-133a regulates calcium signals and cardiac hypertrophy. J Cell Biol. 2012;199(5):783-798.

181. Carrillo ED, EscobarY, González G, et al. Posttranscriptional regulation of the $\beta 2$-subunit of cardiac L-type Ca2+ channels by MicroRNAs during long-term exposure to isoproterenol in rats. $J$ Cardiovasc Pharmacol. 2011;58(5):470-478.

182. Lu Y, Zhang Y, Wang N, et al. MicroRNA-328 contributes to adverse electrical remodeling in atrial fibrillation. Circulation. 2010;122(23): 2378-2387.
Journal of Receptor, Ligand and Channel Research

\section{Publish your work in this journal}

The Journal of Receptor, Ligand and Channel Research is an international, peer reviewed, open access, online journal. The journal welcomes laboratory and clinical findings in the fields of biological receptors, ligands, channel and signal transduction research including: receptors and signaling; ligands; transporters, pores and channels; binding and activation; receptor

\section{Dovepress}

regulation; role of receptors in diseases and their treatment; molecular basis of membrane structure and functions; molecular models of membranes. The manuscript management system is completely online and includes a very quick and fair peer-review system. Visit http://www.dovepress.com/ testimonials.php to read real quotes from published authors. 